\title{
Growth performance and nutrient removal of a Chlorella vulgaris- Rhizobium sp. co-culture during mixotrophic feed-batch cultivation in synthetic wastewater
}

\author{
Lorenza Ferro $^{1}$, Zivan Gojkovic ${ }^{1}$, Raul Muñoz ${ }^{2}$, Christiane Funk ${ }^{1^{*}}$ \\ ${ }^{1}$ Department of Chemistry, Umeå University, 90187 Umeå, Sweden \\ ${ }^{2}$ Institute of Sustainable Processes, University of Valladolid, 47011 Valladolid, Spain
}

${ }^{*}$ Corresponding author

e-mail: christiane.funk@umu.se

\begin{abstract}
The subarctic green algal strain Chlorella vulgaris 13-1, newly isolated from Northern Sweden, and its co-occurring bacterium Rhizobium sp. were tested for their ability to produce valuable biomass and remove nutrients from synthetic wastewater during mixotrophic feed-batch cultivation at multiple hydraulic retention times (HRTs $=7,5$ and 3 days). The algal-bacterial co-culture showed better performance compared to the corresponding axenic cultures (HRT $=7$ days), with a biomass concentration of $0.63 \pm 0.03 \mathrm{~g} / \mathrm{L}$ and removal rates of $49.5 \pm 6.1 \% \mathrm{TOC}, 55.7 \pm 8.04 \% \mathrm{TN}$ and 95.6 $\pm 3.6 \% \mathrm{TP}$ at steady-state. Culture stability and a high nutrient removal capacity were recorded in the algal-bacterial co-culture even at HRTs of 5 and 3 days. Interestingly, reducing the HRT from 7 to 5 days resulted in a higher lipid content of the biomass, further reduction of the HRT to 3 days enhanced both daily biomass productivity (1.03 g/L/day) and nutrient assimilation. Mixotrophic cocultivation of $C$. vulgaris-Rhizobium sp. can successfully be applied for wastewater reclamation in continuous mode at HRT of 3-7 days, and thus is suitable for both summer and winter conditions in Nordic countries.
\end{abstract}


Keywords: algae, bacteria, co-culture, symbiosis, wastewater

\author{
Abbreviations \\ HRT - hydraulic retention time (day) \\ $\mathrm{TN}$ - concentration of total nitrogen in the culture medium (mM) \\ $\mathrm{TP}$ - concentration of total phosphate in the culture medium $(\mathrm{mM})$ \\ TIC - concentration of total inorganic carbon in the culture medium (mM) \\ TOC - concentration of total organic carbon in the culture medium (mM) \\ PFD - photon flux density $\left(\mu \mathrm{mol}_{\mathrm{ph}} / \mathrm{m}^{2} / \mathrm{s}\right)$ \\ SSW - synthetic wastewater
}

\title{
1. Introduction
}

Biological wastewater remediation based on microalgae has been recognized as a low-energy and environmental-friendly alternative compared to conventional wastewater treatment processes (e.g. aerobic activated sludge, anaerobic digestion), due to its low operational costs, simple bioreactor design, low carbon footprint and high nutrient removal efficiency $[1,2]$. Nitrogen and phosphorus, the main pollutants responsible for the eutrophication of aquatic ecosystems, can be recycled from the produced biomass as biofertilizer, additionally the biomass can serve as feedstock for biofuels, or bioplastics production [3,4]. Microalgae also actively contribute to the removal of heavy metals, pharmaceuticals and other emerging contaminants found in urban and/or industrial wastewaters [58]. The presence of other microorganisms, such as heterotrophic and nitrifying bacteria, can improve the efficiency of the process via synergistic interactions (e.g. commensalism, competition, mutualism): photosynthetic oxygen, respiratory carbon dioxide, mineralized nutrients and even vitamins (e.g. cobalamin, other B-vitamins), hormones (e.g. auxin) and/or other mediator molecules (e.g. siderophores, lactones, volatile compounds) are exchanged between algae and bacteria, thus 
promoting biomass productivity and quality, boosting pollutant removal and providing higher robustness of the culture towards changes in the environment [9-13]. These interactions can also help to overcome operational issues: harvesting of the biomass, for example, representing a bottleneck for the feasibility and economics of the process, might be facilitated by the presence of bacteria, which naturally promote bioflocculation of the algae [14]. Recently, we identified a mutualistic relationship between the Nordic microalgal strain Chlorella vulgaris 13-1 and the co-occurring bacterium Rhizobium sp., when co-cultivated in synthetic municipal wastewater in a batch closed system. The microalgal strain Chlorella vulgaris 13-1 belongs to a larger group of microalgae isolated from Northern Sweden [15], suitable for wastewater reclamation in Nordic regions as a result of the acclimation to low temperatures and efficient removal of nitrogen, phosphorus and pharmaceutical compounds $[5,16]$. The bacterial strain identified as Rhizobium sp. was found to naturally co-occur with the original $C$. vulgaris 13-1 culture [17]. The species-specific symbiotic interaction was only detected under mixotrophic conditions and supported by an in-situ $\mathrm{O}_{2} / \mathrm{CO}_{2}$ exchange between the microorganisms and a beneficial reduction of the $\mathrm{pH}$ within the growing medium [17]. During mixotrophic growth, inorganic and organic carbon are used simultaneously in the presence of light, as $\mathrm{CO}_{2}$ is fixed by photosynthesis and organic compounds are oxidized via aerobic respiration. This type of cultivation potentially supports higher growth rates and biomass productivities compared to traditional phototrophic growth (due to a reduced photo-inhibition mediated by the higher cell densities) and heterotrophic growth (as light is used as supplementary energy source) [18], and during Chlorella-Rhizobium co-cultivation resulted in increased biomass and lipid production as well as in superior nutrient removal efficiency [17]. However, knowledge on continuous wastewater treatment and the influence of the hydraulic retention time (HRT, i.e. the average residence time of the wastewater in the photobioreactor) on the stability and performance of algal-bacterial synergies is limited [19-22]. HRTs of 10 to 2 days are typically implemented in algal-bacterial wastewater treatment processes, adjusted depending on the environmental conditions and wastewater 
characteristics in order to avoid washout or inhibitory effects and match the oxygenation capacity of the photobioreactor $[23,24]$.

In this work, the potential of a C. vulgaris-Rhizobium sp. co-culture to continuously remove nutrients and organic matter was assessed and compared to the treatment performance of axenic cultures of $C$. vulgaris and Rhizobium sp. In addition, the influence of HRTs on the performance of the algalbacterial co-culture was investigated. Addressing the growth performance and nutrient assimilation capacity of a subarctic microalgal strain and its natural co-occurring bacterium under mixotrophic semi-continuous conditions, we could show that the co-culture performed better than the corresponding axenic cultures. Reducing the HRT from 7 to 5 days resulted in a higher lipid content of the biomass, further reduction to 3 days enhanced both daily biomass productivity ( $1.03 \mathrm{~g} / \mathrm{L} /$ day) and nutrient assimilation.

\section{Materials and methods}

\subsection{Microalgal and bacterial strains and culture media}

Axenic microalgae (A) and bacteria (B) were isolated from the co-culture $(\mathrm{AB})$ as described in [17]. Pre-inoculum of C. vulgaris and Rhizobium sp. were maintained under sterile conditions in 100 ml Erlenmeyer flasks filled with $30 \mathrm{ml}$ of Bold's basal medium (BBM) [25] and M408 medium [26], respectively, in a thermostatic orbital shaker at $115 \mathrm{rpm}, 25^{\circ} \mathrm{C}$ and $100 \mu \mathrm{mol}_{\mathrm{ph}} / \mathrm{m}^{2} / \mathrm{s}$ (white light). Seven to nine days old pre-inoculum cultures were used to inoculate $500 \mathrm{ml}$ glass flasks filled with $350 \mathrm{ml}$ of the corresponding culture media and bubbled with air under sterile conditions. These cultures were subsequently used to inoculate the sterile photobioreactors to a final concentration of ca. $100 \mathrm{mg} / \mathrm{L}$ of biomass dry weight (thus $200 \mathrm{mg} / \mathrm{L}$ in $\mathrm{AB}$, to keep the same number of individual cells for each type of microbial culture and similar volumetric rate for both algal and bacterial metabolism). 
The microorganisms were grown mixotrophically in sterile synthetic wastewater (SSW) based on BG11 medium [27] supplemented with glucose $(0.5 \mathrm{~g} / \mathrm{L})$, peptone $(0.16 \mathrm{~g} / \mathrm{L})$, meat extract $(0.11$ $\mathrm{g} / \mathrm{L})$, urea $(0.03 \mathrm{~g} / \mathrm{L})$ and $\mathrm{KH}_{2} \mathrm{PO}_{4}(0.02 \mathrm{~g} / \mathrm{L})$ in order to mimic the typical composition of municipal wastewater in terms of total organic carbon (TOC), total nitrogen (TN), and total phosphate (TP) [17]. The initial concentration of nutrients in this SSW was $326 \pm 12 \mathrm{mg} / \mathrm{L} \mathrm{TOC}, 70 \pm 11 \mathrm{mg} / \mathrm{L} \mathrm{TN}, 4.8 \pm$ $1.2 \mathrm{mg} / \mathrm{L}$ TP (corresponding to a $\mathrm{C}: \mathrm{N}: \mathrm{P}$ ratio of ca. $68: 15: 1$ ), with a $\mathrm{pH}$ of $8.5 \pm 0.3$.

\subsection{Cultivation system and experimental set-up}

The continuous cultivation system consisted of two sterile 9 L stirred tank glass photobioreactors (Figure 1). Each photobioreactor was illuminated from one side with a custom-made white LED panel with a photon flux density (PFD) on the panel surface of $650 \mu \mathrm{mol}_{\mathrm{ph}} / \mathrm{m}^{2} / \mathrm{s}$ of photosynthetic active radiation (PAR) under a $12 \mathrm{~h}$ of photoperiod. Each culture was constantly mixed by magnetic agitation at $150 \mathrm{rpm}$. Cultures inside the vessel were bubbled with $1 \mathrm{~L} / \mathrm{min}$ of pre-humidified sterile air. The cultivation system was placed in a temperature-regulated chamber at $20^{\circ} \mathrm{C}$. 
Figure 1. Schematic representation of the continuous cultivation system with a working volume of $9 \mathrm{~L}$ in each

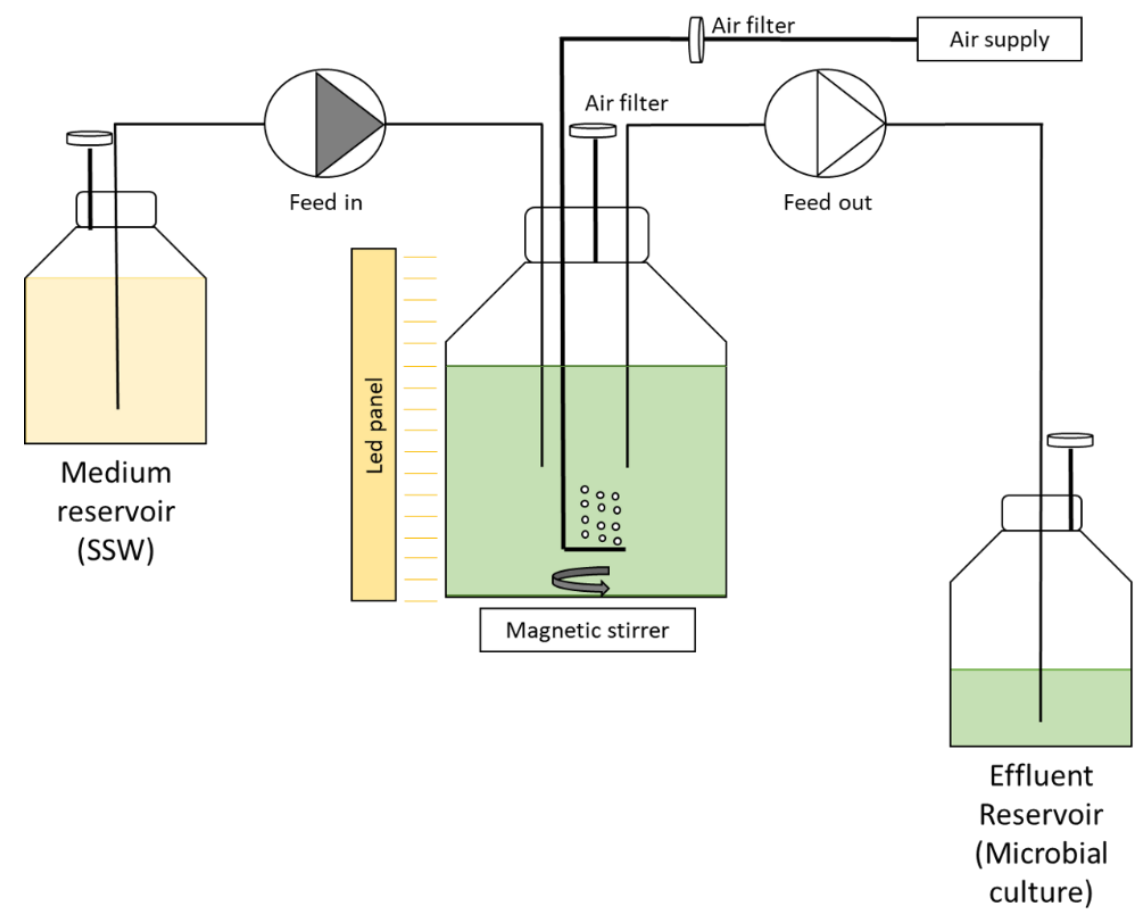

photobioreactor. A predetermined culture volume was replaced daily with fresh sterile synthetic wastewater (SSW) based on the HRT (1.3 L/day for HRT 7; $1.8 \mathrm{~L} /$ day for HRT 5; $3 \mathrm{~L} /$ day for HRT 3).

Three series of continuous cultivations were performed to compare the removal efficiencies of carbon and nutrients and the biomass productivity of the axenic algal culture (A), the axenic bacterial culture (B) and the co-culture (AB) at an HRT of 7 days. The impact of the HRT (7, 5 and 3 days) on the performance of wastewater treatment was investigated on the AB co-culture: The HRT was decreased once the culture reached a steady state (i.e. culture absorbance and biomass concentration remained stable for at least three consecutive measurements [28]. The corresponding volume of the culture was replaced daily by fresh, sterile SSW and the harvested biomass was used to determine culture parameters and nutrient concentrations. All experiments were performed in duplicates.

\subsection{Analytical methods}

The optical density (OD) of the cultures was used to estimate their biomass concentrations. It was determined at wavelengths of 530, 600, 680, and $750 \mathrm{~nm}$ using an UV/Visible spectrophotometer (Varian Carry 50 Bio) in a $10 \mathrm{~mm}$ light path polystyrene cuvette. Biomass concentrations $\left(\mathrm{C}_{\mathrm{x}}\right)$ of the 
cultures, expressed as dry weight concentrations (g/L), were also determined daily by filtration of known volumes of culture over pre-dried and pre-weighted glass fiber filters (Whatman GC) and measuring the weight increase of the dried filters, according to [29]. To completely retain the bacterial cells (Rhizobium sp. has a size of 0.5-0.9 $\mu \mathrm{m}$ in width and 1.2-3.0 $\mu \mathrm{m}$ in length) double filters were used. The daily biomass productivity (g/L/day) was calculated according to $P_{\text {daily }}=C_{x} \cdot Q_{\text {out }}$, where Qout is the effluent flowrate.

Samples for electron imaging (scanning electron microscope, SEM) were prepared as follows: cultured cells were fixed overnight at $4^{\circ} \mathrm{C}$ with $2.5 \%$ glutaraldehyde in $0.1 \mathrm{M}$ sodium cacodylate buffer. Samples were sedimented on glass coverslips, dehydrated in a series of graded ethanol, critical point dried and coated with $2 \mathrm{~nm}$ platinum. Microbial cell morphology was analyzed by fieldemission scanning electron microscopy (FESEM; Carl Zeiss Merlin) using an in-chamber secondary electron detector at accelerating voltage of $5 \mathrm{kV}$ and probe current of $120 \mathrm{pA}$.

Total organic carbon (TOC), total nitrogen (TN) and total phosphate (TP) of the SSW were performed spectrophotometric according to manufacturer's instructions (Hach-Lange, Germany) using the supernatants after centrifuging fresh culture samples. Nutrient concentrations were analyzed every third day of cultivation. The removal efficiencies of TOC, TN and TP (RE, \%) under steady state were calculated according to the equation [10] $R E=\frac{\left(Q_{\text {in }} C_{\text {in }}-Q_{\text {out }} C_{\text {out }}\right)}{Q_{\text {in }} C_{\text {in }}} \cdot 100$, where $Q_{\text {in }}$ represents the influent flowrate $(\mathrm{L} / \mathrm{d})$ and $\mathrm{Q}_{\text {out }}$ the effluent flowrate $(\mathrm{L} / \mathrm{d}) ; \mathrm{C}_{\text {in }}$ and $\mathrm{C}_{\text {out }}$ are the influent and effluent average concentrations of the monitored nutrient, respectively (mg/L).

Biomass samples were harvested every third day from the algae-bacteria co-cultures, freeze-dried and analysed by diffuse reflectance FTIR spectroscopy, using a Bruker IFS 66 v/S instrument under vacuum conditions (4 mbar), according to [30]. Samples (5-10 mg) were prepared and FTIR spectra recorded and processed as described in [16]. The fingerprint region of each FTIR spectrum (800$1800 \mathrm{~cm}^{-1}$ ) was normalized to the total peak area and the relative contribution (\%) of lipids, proteins 
and carbohydrates was derived from the corresponding peak area at $1710-1799 \mathrm{~cm}^{-1}(-\mathrm{C}=\mathrm{O}$, lipids), $1580-1710 \mathrm{~cm}^{-1}$ (amide I, proteins) and $951-1135 \mathrm{~cm}^{-1}$ (-C-O-C-, carbohydrates).

\subsection{Statistical analysis}

All the experimental results represent the mean \pm standard deviation (SD) of two biological treatments performed in two independent photobioreactors and analyzed with independent technical triplicates. Kruskal-Wallis rank sum test was conducted to assess significant differences between different cultures and treatments. The Dunn post-hoc test was used to assess significant differences between the treatments within the same group. The differences were considered significant at $\mathrm{p}<$ 0.05 .

\section{Results and Discussion}

\subsection{Growth and nutrient removal capacity comparing the axenic cultures with the co-culture in feed-batch cultivation at an HRT of 7 days}

The C. vulgaris- Rhizobium sp. co-culture (AB) performed significantly better compared to the axenic algae (A) and bacteria (B) cultures in terms of both biomass growth and SSW reclamation under mixotrophic cultivation in continuous mode at the HRT of 7 days (Figure 2), confirming our previous results in closed batch system [17]. The biomass concentration under steady state was significantly higher in $\mathrm{AB}(0.63 \pm 0.03 \mathrm{~g} / \mathrm{L})$ compared to $\mathrm{A}(0.52 \pm 0.02 \mathrm{~g} / \mathrm{L})$ and $\mathrm{B}(<0.05 \mathrm{~g} / \mathrm{L})$ (Figure 2a), thus demonstrating the higher productivity of the algae-bacteria consortium under mixotrophic growth mediated by the simultaneous presence of light and organic carbon as energy sources. Although starting with an initial total biomass concentration of $200 \mathrm{mg} / \mathrm{L}$ in the co-culture (100 mg/L A + $100 \mathrm{mg} / \mathrm{L} \mathrm{B})$, similar results would have been obtained with half of the inoculum for each microbial culture, but in a considerably longer time due to the reduced volumetric rate of 
oxygenation and organic matter degradation of microalgae and bacteria, respectively. A similar TN removal (RE 50\%) from SSW was observed in all the three systems (effluent TN concentrations of $37.2 \pm 1.5,34.5 \pm 0.7,31.7 \pm 1.8 \mathrm{mg} / \mathrm{L}$ for $\mathrm{A}, \mathrm{B}$ and $\mathrm{AB}$ respectively, Figure $2 \mathrm{c})$, suggesting a competition for nitrogen between the two microorganisms in the co-culture. This is in contrast to observations on a co-culture of $C$. protothecoides-Brevundimonas diminuta cultivated in a similar synthetic wastewater, but resulting in higher TN consumption compared to the corresponding axenic cultures [22]. Different algae-bacteria consortia in wastewater treatment applications therefore behave very specific. In our setup the assimilation of TOC was much higher ( $\mathrm{RE}>50 \%$ ) in B (effluent TOC concentrations of $188.5 \pm 13 \mathrm{mg} / \mathrm{L}$ ) and AB (effluent TOC concentrations of $167.3 \pm 13.5 \mathrm{mg} / \mathrm{L}$ ) than in A (effluent TOC concentrations of $266.5 \mathrm{mg} / \mathrm{L}$ ) (Figure 2b), pointing to an active role of Rhizobium during assimilation of organic carbon and its removal from synthetic wastewater, lacking competition by the algae. The assimilation of glucose in axenic C. vulgaris (likely taking place during the 12 hours darkness) could be compensated by an active release of organic carbon from the algae in form of dissolved organic matter (DOM), as already observed under batch-cultivation [17]. Furthermore, other substrates than glucose could exert different effects on mixotrophic growth of $C$. vulgaris, as reported for $C$. protothecoides cultures in the presence of glycerol, ethanol or sodium acetate [31]. Interestingly, in the algae-bacteria co-culture, but not in A or B, TP abatement was almost complete $(\mathrm{RE} \sim 96 \%)$ (effluent TP concentration $<0.3 \mathrm{mg} / \mathrm{L})$ (Figure $2 \mathrm{~d}$ ), indicating a possible luxurious phosphate uptake by Chlorella, enhanced by the presence of Rhizobium. This specific consortium therefore represents a very powerful tool for efficient biological phosphorus removal from wastewater, a pollutant, which typically has to be reduced via expensive physicochemical methods in conventional treatment plants [32]. 

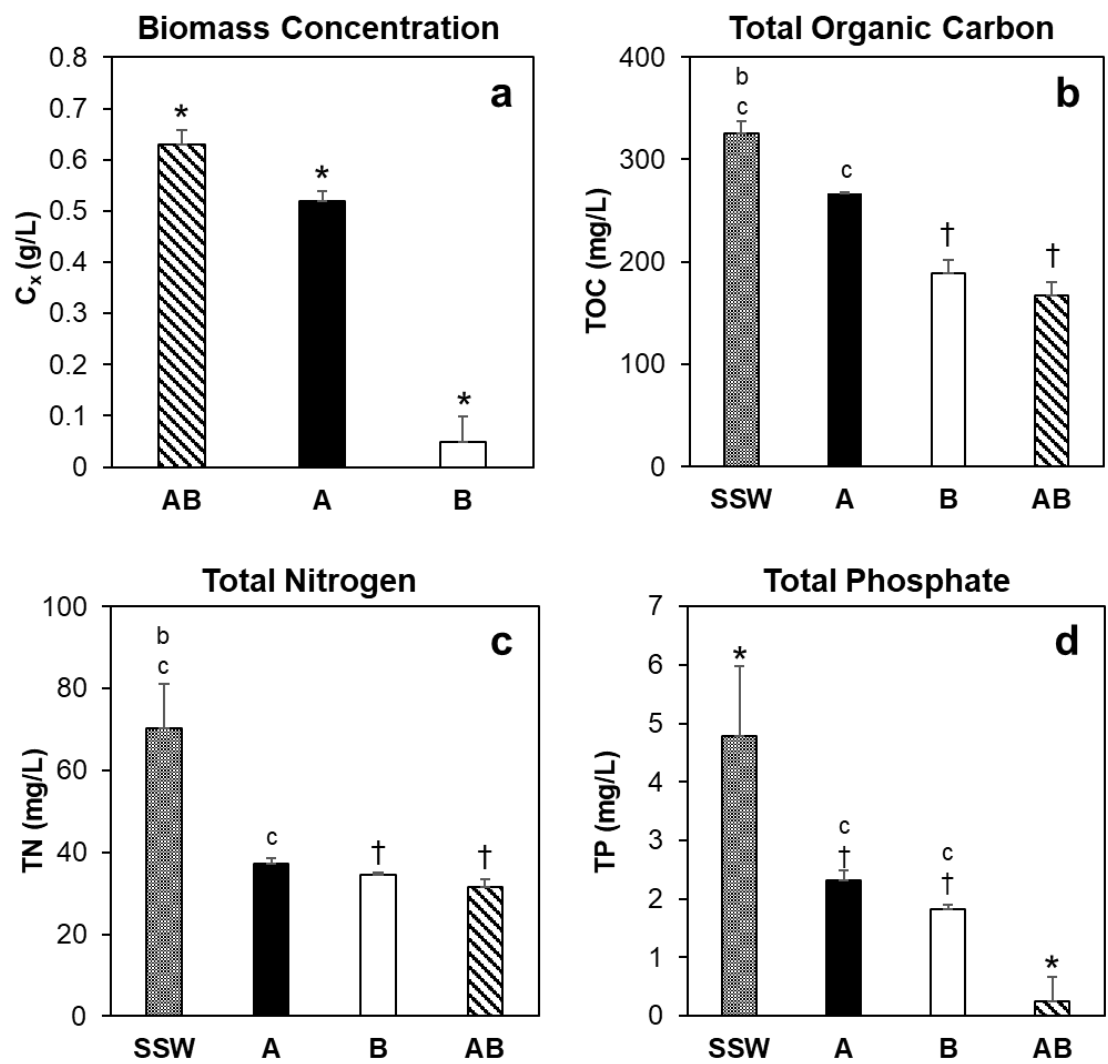

Figure 2. Average concentrations of biomass $(\mathbf{a})$, total organic carbon (b), total nitrogen $(\mathbf{c})$ and total phosphate (d) of axenic C. vulgaris 13-1 (A), axenic Rhizobium sp. (B) and algal-bacterial co-culture (AB) during continuous cultivation in SSW at HRT of 7. Mean \pm standard deviation (SD) of two independent biological replicates and three technical replicates. Significant differences (Kruskal-Wallis and Dunn post-hoc test, $p=$ $0.05): *=$ Significantly different to all; $\uparrow=$ Significantly different from SSW; a=Significantly different to A; $\mathrm{b}=$ Significantly different to $\mathrm{B} ; \mathrm{c}=$ Significantly different to $\mathrm{AB}$.

Overall, our results demonstrate the feasibility of C. vulgaris-Rhizobium sp. continuous cocultivation and its potential applicability to municipal wastewater treatment: nitrogen, phosphorus and organic carbon were removed simultaneously during mixotrophic growth in a single biological step. No external addition of $\mathrm{O}_{2}$ or $\mathrm{CO}_{2}$ was needed to support microbial growth as a result of the efficient gas exchange between microalgae and bacteria, which further reduces the operational costs of the process. 
Scanning electron microscopy was performed on cells of the axenic and co-cultures (Figure 3). A close physical interaction between the algal and bacterial microorganisms became evident in the SEM images of $C$. vulgaris and Rhizobium sp. in co-culture (Figure 3c, d), which would allow a direct exchange of gases and/or other promoting substances at the cell surface in the symbiotic relationship. A similar intimate microbial interaction has been observed between the marine microalga Emiliania huxleyi and the parasitic bacterium Phaeobacter inhibens, which is known to kill the algal host after an initial algal growth promotion [33]. Based on our SEM analysis, we hypothesize a physical microbial contact to be necessary also for the establishment of positive mutualistic interactions, as shown for C. vulgaris and Rhizobium sp. under the conditions tested. Particularly, Rhizobium cells formed aggregates with microalgae cells (Figure 3c), a mechanism known to be mediated either by polysaccharides or proteins produced at the surface of the bacterial cell wall, or by charge neutralization or electrostatic bridging between algal and/or bacterial EPS (extracellular polymeric substances) [34]. This aggregation explains the improved settling and harvesting behavior observed for various unicellular microalgal-bacterial communities [35,36]; a relatively faster flocculation was also observed in samples of our Chlorella-Rhizobium consortium taken along the experiments, compared to the corresponding axenic cultures (not shown), although no detailed measurements on the sedimentation rate of the algae-bacteria flocs were performed in this study. This phenomenon demands further investigations as bio-flocculation enhanced by bacteria can represent an efficient, environmental friendly and low-cost technology for microalgal harvesting [37]. 

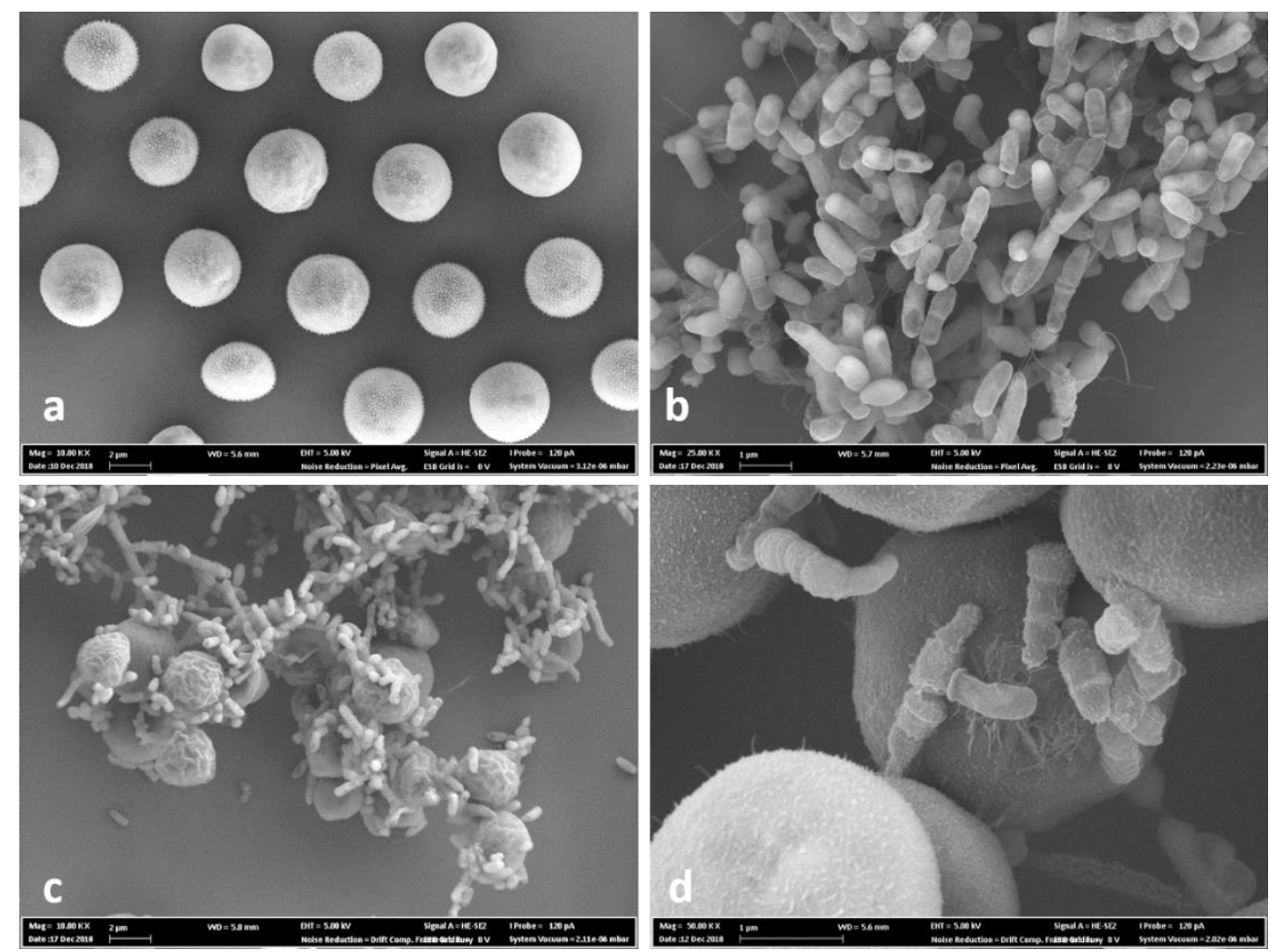

Figure 3. Scanning electron microscope (SEM) images of the axenic alga $C$. vulgaris 13-1 (a), the axenic bacterium Rhizobium sp. (b) and the algal-bacterial co-culture (c, d) at $10(\mathbf{a}, \mathbf{c}), 25$ (b) and $50 \mathrm{~K}$ (d) X magnification.

\subsection{Influence of the HRT on the performance of $C$. vulgaris- Rhizobium sp. co-culture during wastewater treatment}

To investigate the impact of the HRT on the performance of the algal-bacterial co-culture (AB) and to assess its full biodegradation potential, the HRT of 7 days was reduced to 5 and 3 days, when the culture was in steady state; on day 9 of the continuous culture the HRT was decreased from 7 to 5 days and then on day 22 to 3 days. Biomass concentrations of the co-culture at steady-state decreased to $0.46 \pm 0.12 \mathrm{~g} / \mathrm{L}$ and $0.34 \pm 0.10 \mathrm{~g} / \mathrm{L}$ with decreasing HRTs to 5 and 3 days, respectively, as a result of the increased dilution (Figure 4a). At steady-state, the maximal growth rate $\left(\mu_{\max }\right)$ of the algae-bacteria co-culture was correlated equally to the dilution rate, i.e. $0.14,0.20$ and $0.331 /$ day at an HRT 7, 5 and 3, respectively, while the removal rates of TOC, TN and TP remained relatively 
constant even at shorter HRTs, demonstrating the robustness of the algae-bacteria system in the continuous treatment process. At steady-state TOC concentrations of $152.8 \pm 27.2$ and $127.0 \pm 13.1$ $\mathrm{mg} / \mathrm{L}, \mathrm{TN}$ of $25.9 \pm 5.5$ and $21.7 \pm 2.2 \mathrm{mg} / \mathrm{L}$ and $\mathrm{TP}$ of $0.11 \pm 0.07$ and $0.07 \pm 0.06 \mathrm{mg} / \mathrm{L}$ were obtained at HRT 5 and 3, respectively (Figure 4b-d).
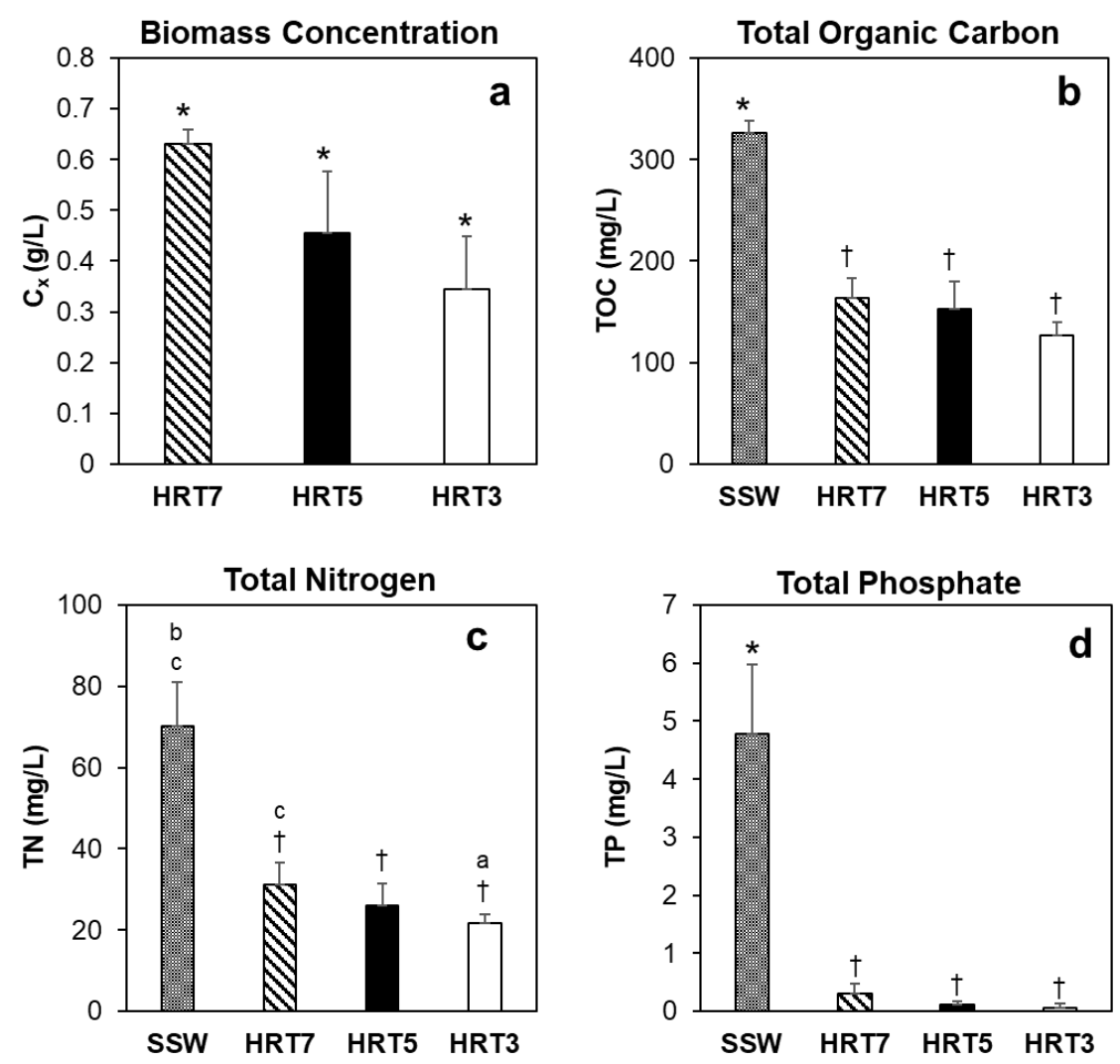

Figure 4. Biomass concentrations (a), total organic carbon (b), total nitrogen (c) and total phosphate (d) of the C. vulgaris 13-1-Rhizobium sp. co-culture in steady state during continuous cultivation in SSW at HRTs of 7, 5 and 3 days. Mean \pm standard deviation (SD) of two independent biological replicates and three technical replicates. Significant differences (Kruskal-Wallis and Dunn post-hoc test, $p=0.05$ ): *= Significantly different to all; $\uparrow=$ Significantly different to SSW; $a=$ Significantly different to HRT 7; b=Significantly different to HRT 5; c=Significantly different to HRT 3 .

The corresponding removal rates are presented in Table 1, together with the daily biomass productivities $\left(\mathrm{P}_{\text {daily }}\right)$ of the co-culture at HRTs of 7, 5 and 3 days. No difference was observed 
between HRTs 7 and $5\left(\mathrm{P}_{\text {daily }}=0.82 \mathrm{~g} / \mathrm{L} /\right.$ day $)$ likely due to the similar flow rates $(1.3$ and $1.8 \mathrm{~L} /$ day, respectively) leading to similar biomass concentrations at steady-state ( 0.6 and $0.5 \mathrm{~g} / \mathrm{L}$, respectively). The culture productivity at HRT 3 was, however, much higher (1.03 g/L/day), despite lower biomass concentration $(0.3 \mathrm{~g} / \mathrm{L})$, which explains the stimulated uptake of nutrients from the SSW and higher incorporation of $\mathrm{N}$ and $\mathrm{P}$ into the biomass. Similarly, the highest biomass productivity has been reached for a continuous culture of Chlorella minutissima at the same dilution rate of 0.33 1/day [38]. Enhanced nutrient consumption and high microalgae biomass productivity caused by lower HRTs was also observed during continuous cultivation of $C$. vulgaris in treated sewage in membrane photobioreactors $[39,40]$. Thus, as no washout effect was observed at HRT 3 , this short residence time seems to be suitable to maintain a long-term cultivation and achieve an efficient removal of pollutants, even at large scale outdoors, although the risk of contamination by detrimental microorganisms might increase [41]. The robustness of the Chlorella-Rhizobium consortium under real wastewater treatment needs to be carefully evaluated, due to the complexity of this system. Maintaining the optimal conditions, which maximize this species-specific mutualistic interaction can, however, represent a competitive advantage over other native species, especially if growth rates of both desired algae and bacteria are kept at their optimum. This phenomenon known as "competitive exclusion" has been observed in aquaculture systems $[42,43]$.

The $\mathrm{pH}$ of the culture remained at $9.5 \pm 0.5$ along the experiments independent of the HRT, confirming bacteria being beneficial to control the $\mathrm{pH}$ in the co-culture (balancing the raising $\mathrm{pH}$ of algal photosynthesis), as previously observed in batch cultivation system [17], and also showing the good tolerance of $C$. vulgaris to a moderate alkaline environment.

Table 1. Daily biomass productivity, $\mathrm{pH}$ and nutrient removal rates in the algal-bacterial co-culture as a function of the HRT. Mean \pm standard deviation (SD) of two independent biological replicates and three technical replicates. 


\begin{tabular}{ccccccc}
\hline $\begin{array}{c}\text { HRT } \\
\text { day }\end{array}$ & $\begin{array}{c}\text { Flow rate }(\mathbf{Q}) \\
\text { L/day }\end{array}$ & $\mathbf{p H}$ & $\begin{array}{c}\mathbf{P}_{\text {daily }} \\
\text { g/L/day }\end{array}$ & TOC $(\%)$ & TN $(\%)$ & TP $(\%)$ \\
\hline 7 & 1.3 & $9.8 \pm 0.5$ & $0.84 \pm 0.01$ & $49.5 \pm 6.1$ & $55.7 \pm 8.0$ & $95.6 \pm 3.6$ \\
5 & 1.8 & $9.7 \pm 0.2$ & $0.82 \pm 0.01$ & $52.9 \pm 8.4$ & $63.1 \pm 7.9$ & $97.9 \pm 1.2$ \\
3 & 3.0 & $9.5 \pm 0.2$ & $1.03 \pm 0.02$ & $60.8 \pm 4.0$ & $69.1 \pm 3.1$ & $98.9 \pm 1.3$ \\
\hline
\end{tabular}

\subsection{Microbial biomass composition based on FTIR spectroscopic analysis}

Fourier Transformed Infrared (FTIR) spectroscopy, a sensitive and reliable high-throughput method to determine the biochemical composition of biological samples including microalgae [4446], was used to identify the relative contribution (\%)of proteins, carbohydrates and lipids in the biomass of the algal-bacterial co-culture (Figure 5). Due to their larger contribution in the total biomass, the IR signal was assumed to derive mainly from $C$. vulgaris cells. During continuous cultivation at an HRT of 7 the content of lipids and carbohydrates increased with cultivation time, while the protein content decreased, a well-known response to nutrient depletion (i.e. $\mathrm{N}$ and/or $\mathrm{P}$ limitation) [47]. At an HRT of 5, the relative amount of lipids further increased to $8.1 \%$ on day 21 compared to the initial level of $7.5 \%$ on day 9 (and therefore doubled from the initial amount of $4.9 \%$ ), at the expense of carbohydrates (a decrease from $28 \%$ to $24 \%$ ). In our previous study using a closed-batch system, the lipid content of $C$. vulgaris improved by a factor of 13 due to the symbiotic interaction with Rhizobium under mixotrophic growth [17]. This stimulating effect was confirmed also during continuous co-cultivation at both HRTs of 7 and 5 days, although the molecular mechanisms behind this phenomenon deserve further investigations. Indeed, the interaction with cogrowing bacteria has been shown to induce considerable changes in the metabolism of microalgae, including enhanced lipid accumulation or carbohydrate/starch content under various culturing conditions [48-50]. Rhizobium, in particular, could stimulate the oil productivity of an Ankistrodesmus sp. strain, increasing the accumulation of important omega-3 fatty acids in the microalgae cells [51]. On the contrary, the concentration of lipids was significantly reduced in two 
species of benthic diamonds growing in the presence of their natural co-occurring bacteria, suggesting that the effect of bacteria on the algal biomass composition can dramatically change depending on the microbial species [52].

Switching to HRT 3 the lipid content slightly decreased from $8.1 \%$ to $6.6 \%$, while the protein content increased (from $25.2 \%$ to $26.3 \%$ ), similarly to what was observed by Lee and co-workers, when cultivating a microalgal consortium under semi-continuous operation at 3-day HRT in secondary effluent wastewater (reduced lipid content, but higher biomass productivity compared to a 6-day HRT) [53]. The reduction in lipid concentration could be therefore related to a sufficient nutrient supply under the lowest HRT tested, which is known to prevent the accumulation of storage compounds in the algal biomass [54], overcoming the stimulatory effect of bacteria.

\section{Biomass composition}

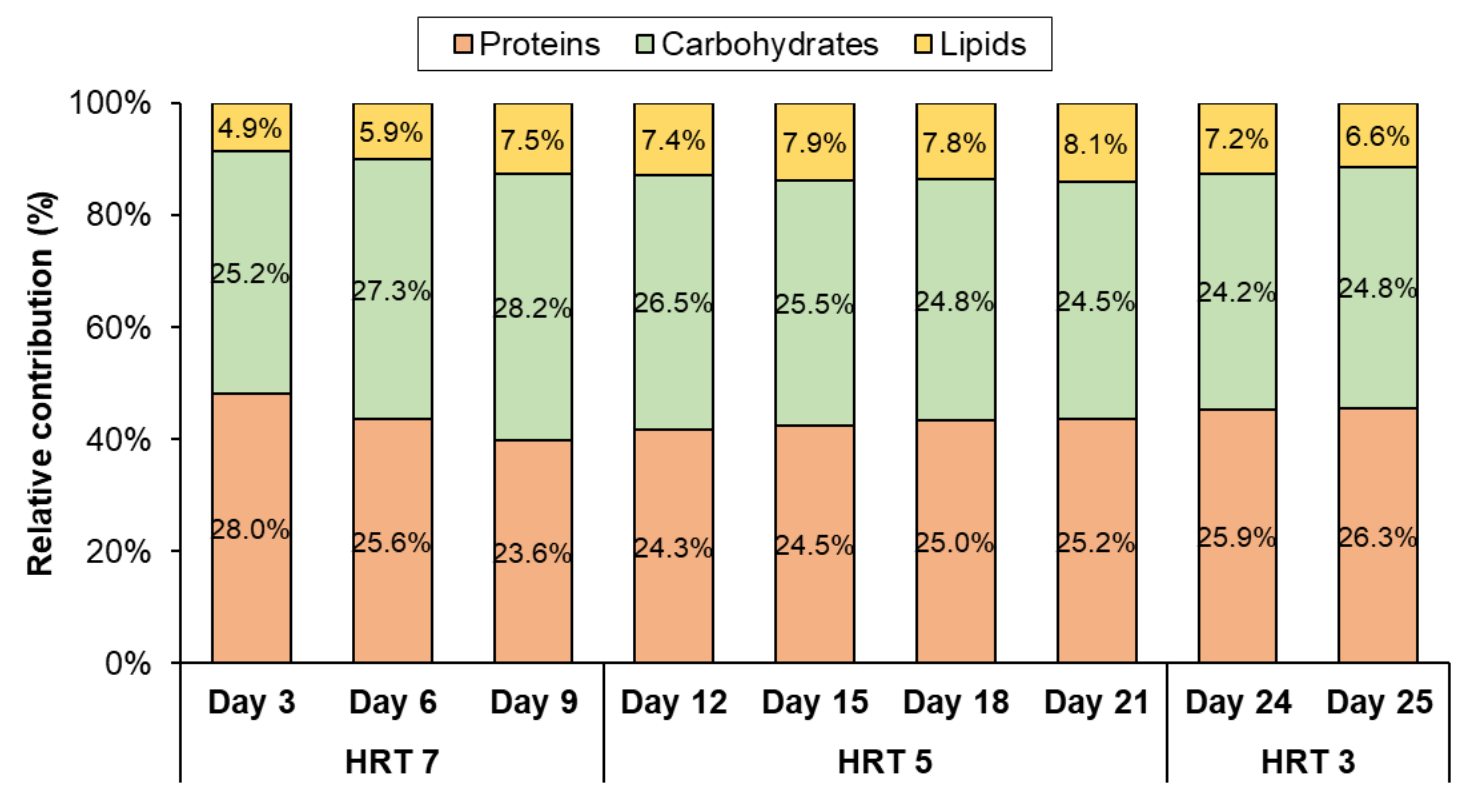

Figure 5. Composition (relative contribution \%) of the biomass in the C. vulgaris-Rhizobium sp. co-culture (AB) at HRTs of 7 (day 1-9), 5 (day 10-21) and 3 (day 22-25) measured by FTIR spectrometry. The spectra were normalized to total area, integrated FTIR peak areas were used to estimate the content of proteins (1580$\left.1715 \mathrm{~cm}^{-1}\right)$, carbohydrates $\left(951-1135 \mathrm{~cm}^{-1}\right)$ and lipids $\left(1715-1780 \mathrm{~cm}^{-1}\right)$. 
In summary, our results point out that the C. vulgaris-Rhizobium sp. co-culture can accumulate energy-rich molecules such as lipids and carbohydrates in its biomass under prolonged cultivation, but carbon partitioning between these two components is strictly influenced by the HRT used in the process. Thus, biomass composition could be redirected towards the desired components by carefully changing the residence time of the culture medium, while maintaining satisfactory biomass productivities (> $80 \mathrm{~g} / \mathrm{L} /$ day) and wastewater treatment efficiencies (removal of 50-60\% TOC, 5570\% TN, 96-99\% TP).

\section{Conclusions}

The Nordic microalga C. vulgaris 13-1, co-cultivated mixotrophically in continuous mode with its naturally co-occurring bacterium Rhizobium sp., was able to produce valuable biomass and efficiently removed nutrients from synthetic wastewater in a series with decreasing HRTs $(7,5$ and 3 days). Highest biomass concentration was obtained at HRT 7, highest lipid accumulation was observed at HRT 5, whereas the highest daily biomass productivity and nutrient removal efficiency was achieved at an HRT of 3 days. We can conclude that the species-specific symbiotic relationship between these two microorganisms offers a potential strategy for wastewater reclamation coupled with the production of energy-rich biomass in mixotrophic continuous processes within an HRT range of 7 to 3 days, which is suitable for Nordic areas. Carbon partitioning leading to lipid- or carbohydrate accumulation can be influenced by the HRT used in the process.

\section{Author contributions}

All authors designed the experiments. Lorenza Ferro and Zivan Gojkovic build-up the reactors, performed the experimental work, data collection, analysis and interpretation under the supervision 
of Raul Muñoz and Christiane Funk. All the authors were involved in the preparation of the manuscript and approved its submission.

\section{Acknowledgements}

This work was supported by the Swedish Energy Agency (Grant no. 2018-017772, project: 48007-1), Vinnova (2017-03301), the NordForsk NCoE programme "NordAqua" (Project no. 82845) and Umeå University. The authors would like to thank András Gorzsás from the Vibrational Spectroscopy Core Facility (ViSP) at Umeå University (Sweden) for valuable help with FTIR spectra acquisition and analysis, and Cheng Choo Lee (Nikki) from the Umeå Core Facility Electron Microscopy (UCEM) at Umeå University (Sweden) for the technical assistance with the SEM imaging. The European Network for Algal-Bioproducts (EUALGAE Cost Action ES1408) is kindly acknowledged for networking and knowledge transfer. The regional government of Castilla y Leon is also gratefully acknowledge (CLU 2017-09).

No conflicts, informed consent, human or animal rights applicable.

\section{References}

[1] C. Alcántara, E. Posadas, B. Guieysse, R. Muñoz, Microalgae-based Wastewater Treatment, Handb. Mar. Microalgae Biotechnol. Adv. (2015) 439-455. doi:10.1016/B978-0-12-800776-1.00029-7.

[2] S. Lage, Z. Gojkovic, C. Funk, F. Gentili, Algal Biomass from Wastewater and Flue Gases as a Source of Bioenergy, Energies. 11 (2018) 664. doi:10.3390/en11030664.

[3] L. Gouveia, S. Graça, C. Sousa, L. Ambrosano, B. Ribeiro, E.P. Botrel, P.C. Neto, A.F. Ferreira, 
C.M. Silva, Microalgae biomass production using wastewater: Treatment and costs. Scale-up considerations., Algal Res. 16 (2016) 167-176. doi:10.1016/j.algal.2016.03.010.

[4] F.G. Acién, C. Gómez-Serrano, M.M. Morales-Amaral, J.M. Fernández-Sevilla, E. Molina-Grima, Wastewater treatment using microalgae: how realistic a contribution might it be to significant urban wastewater treatment?, Appl. Microbiol. Biotechnol. 100 (2016) 9013-9022. doi:10.1007/s00253016-7835-7.

[5] Z. Gojkovic, R.H. Lindberg, M. Tysklind, C. Funk, Northern green algae have the capacity to remove active pharmaceutical ingredients, Ecotoxicol. Environ. Saf. 170 (2019) 644-656. doi:10.1016/j.ecoenv.2018.12.032.

[6] V. Matamoros, R. Gutiérrez, I. Ferrer, J. García, J.M. Bayona, Capability of microalgae-based wastewater treatment systems to remove emerging organic contaminants: A pilot-scale study, J. Hazard. Mater. 288 (2015) 34-42. doi:10.1016/j.jhazmat.2015.02.002.

[7] F.G. Gentili, J. Fick, Algal cultivation in urban wastewater: an efficient way to reduce pharmaceutical pollutants, J. Appl. Phycol. (2017). doi:10.1007/s10811-016-0950-0.

[8] K. Suresh Kumar, H.-U. Dahms, E.-J. Won, J.-S. Lee, K.-H. Shin, Microalgae - A promising tool for heavy metal remediation, Ecotoxicol. Environ. Saf. 113 (2015) 329-352. doi:10.1016/j.ecoenv.2014.12.019.

[9] R. Muñoz, B. Guieysse, Algal-bacterial processes for the treatment of hazardous contaminants: A review, Water Res. 40 (2006) 2799-2815. doi:10.1016/j.watres.2006.06.011.

[10] E. Posadas, P.A. García-Encina, A. Soltau, A. Domínguez, I. Díaz, R. Muñoz, Carbon and nutrient removal from centrates and domestic wastewater using algal-bacterial biofilm bioreactors, Bioresour. Technol. 139 (2013) 50-58. doi:10.1016/j.biortech.2013.04.008.

[11] J.L. Fuentes, I. Garbayo, M. Cuaresma, Z. Montero, M. González-Del-Valle, C. Vílchez, Impact of microalgae-bacteria interactions on the production of algal biomass and associated compounds, Mar. Drugs. 14 (2016). doi:10.3390/md14050100.

[12] A.L. Gonçalves, J.C.M. Pires, M. Simões, A review on the use of microalgal consortia for wastewater 
treatment, Algal Res. 24 (2017) 403-415. doi:10.1016/j.algal.2016.11.008.

[13] E. Amavizca, Y. Bashan, C.M. Ryu, M.A. Farag, B.M. Bebout, L.E. De-Bashan, Enhanced performance of the microalga Chlorella sorokiniana remotely induced by the plant growth-promoting bacteria Azospirillum brasilense and Bacillus pumilus, Sci. Rep. 7 (2017) 1-11. doi:10.1038/srep41310.

[14] T.D.P. Nguyen, T.V.A. Le, P.L. Show, T.T. Nguyen, M.H. Tran, T.N.T. Tran, S.Y. Lee, Bioflocculation formation of microalgae-bacteria in enhancing microalgae harvesting and nutrient removal from wastewater effluent, Bioresour. Technol. 272 (2019) 34-39. doi:10.1016/j.biortech.2018.09.146.

[15] L. Ferro, F.G. Gentili, C. Funk, Isolation and characterization of microalgal strains for biomass production and wastewater reclamation in Northern Sweden, Algal Res. 32 (2018) 44-53. doi:10.1016/j.algal.2018.03.006.

[16] L. Ferro, A. Gorzsás, F.G. Gentili, C. Funk, Subarctic microalgal strains treat wastewater and produce biomass at low temperature and short photoperiod, Algal Res. 35 (2018) 160-167. doi:10.1016/j.algal.2018.08.031

[17] L. Ferro, M. Colombo, E. Posadas, C. Funk, R. Muñoz, Elucidating the symbiotic interactions between a locally isolated microalga Chlorella vulgaris and its co-occurring bacterium Rhizobium sp. in synthetic municipal wastewater, J. Appl. Phycol. (2019). doi:10.1007/s10811-019-1741-1.

[18] J. Zhan, J. Rong, Q. Wang, Mixotrophic cultivation, a preferable microalgae cultivation mode for biomass/bioenergy production, and bioremediation, advances and prospect, Int. J. Hydrogen Energy. 42 (2017) 8505-8517. doi:10.1016/j.ijhydene.2016.12.021.

[19] J.M. Valigore, P.A. Gostomski, D.G. Wareham, A.D. O'Sullivan, Effects of hydraulic and solids retention times on productivity and settleability of microbial (microalgal-bacterial) biomass grown on primary treated wastewater as a biofuel feedstock, Water Res. 46 (2012) 2957-2964. doi:10.1016/j.watres.2012.03.023.

[20] Y. Takabe, T. Hidaka, J. Tsumori, M. Minamiyama, Effects of hydraulic retention time on cultivation 
of indigenous microalgae as a renewable energy source using secondary effluent, Bioresour. Technol. 207 (2016) 399-408. doi:10.1016/j.biortech.2016.01.132.

[21] A. Anbalagan, S. Schwede, C.-F. Lindberg, E. Nehrenheim, Influence of hydraulic retention time on indigenous microalgae and activated sludge process, Water Res. 91 (2016) 277-284. doi:10.1016/j.watres.2016.01.027.

[22] M. Pastore, E. Sforza, Exploiting symbiotic interactions between Chlorella protothecoides and Brevundimonas diminuta for an efficient single-step urban wastewater treatment, Water Sci. Technol. 78 (2018) 216-224. doi:10.2166/wst.2018.155.

[23] E. Posadas, P.A. García-Encina, A. Domínguez, I. Díaz, E. Becares, S. Blanco, R. Muñoz, Enclosed tubular and open algal-bacterial biofilm photobioreactors for carbon and nutrient removal from domestic wastewater, Ecol. Eng. 67 (2014) 156-164. doi:10.1016/j.ecoleng.2014.03.007.

[24] K. Larsdotter, WasteWater treatment With microalgae - a literature review, Vatten. 62 (2006) 31-38.

[25] H.W. Bischoff, H.C. Bold, Some soil algae from enchanted rock and related Algal species, in: Phycol. Stud. (No. 4) Publ. / Univ. Texas (No. 6318), 1963: pp. 1-95.

[26] A.T.C. Collection, Catalogue of bacteria and phages, (1989).

[27] R.Y. Stanier, R. Kunisawa, M. Mandel, G. Cohen-Bazire, Purification and properties of unicellular blue-green algae (order Chroococcales)., Bacteriol. Rev. 35 (1971) 171-205.

[28] Ž. Gojkovic, I. Garbayo-Nores, V. Gómez-Jacinto, T. García-Barrera, J.-L. Gómez-Ariza, I. Márová, C. Vílchez-Lobato, Continuous production of selenomethionine-enriched Chlorella sorokiniana biomass in a photobioreactor, Process Biochem. 48 (2013) 1235-1241. doi:10.1016/j.procbio.2013.06.013.

[29] Ž. Gojkovic, C. Vílchez, R. Torronteras, J. Vigara, V. Gómez-Jacinto, N. Janzer, J.L. Gómez-Ariza, I. Márová, I. Garbayo, Effect of selenate on viability and selenomethionine accumulation of Chlorella sorokiniana grown in batch culture, Sci. World J. 2014 (2014). doi:10.1155/2014/401265.

[30] A. Gorzsás, B. Sundberg, Chemical Fingerprinting of Arabidopsis Using Fourier Transform Infrared (FT-IR) Spectroscopic Approaches, in: 2014: pp. 317-352. doi:10.1007/978-1-62703-580-4_18. 
[31] E. Sforza, R. Cipriani, T. Morosinotto, A. Bertucco, G.M. Giacometti, Excess CO 2 supply inhibits mixotrophic growth of Chlorella protothecoides and Nannochloropsis salina, Bioresour. Technol. 104 (2012) 523-529. doi:10.1016/j.biortech.2011.10.025.

[32] J.T. Bunce, E. Ndam, I.D. Ofiteru, A. Moore, D.W. Graham, A Review of Phosphorus Removal Technologies and Their Applicability to Small-Scale Domestic Wastewater Treatment Systems, Front. Environ. Sci. 6 (2018). doi:10.3389/fenvs.2018.00008.

[33] E. Segev, H. Vlamakis, L. Chai, R. Kolter, T.P. Wyche, K.H. Kim, J. Clardy, J. Petersen, C. Ellebrandt, N. Barteneva, J.N. Paulson, Dynamic metabolic exchange governs a marine algalbacterial interaction, Elife. 5 (2016) 1-28. doi:10.7554/eLife.17473.

[34] A. Pugazhendhi, S. Shobana, P. Bakonyi, N. Nemestóthy, A. Xia, R. Banu J, G. Kumar, A review on chemical mechanism of microalgae flocculation via polymers, Biotechnol. Reports. 21 (2019) e00302. doi:10.1016/j.btre.2018.e00302.

[35] H. Wang, H.D. Laughinghouse, M.A. Anderson, F. Chen, E. Willliams, A.R. Place, O. Zmora, Y. Zohar, T. Zheng, R.T. Hill, Novel Bacterial Isolate from Permian Groundwater, Capable of Aggregating Potential Biofuel-Producing Microalga Nannochloropsis oceanica IMET1, Appl. Environ. Microbiol. 78 (2012) 1445-1453. doi:10.1128/AEM.06474-11.

[36] R.J. Powell, R.T. Hill, Rapid Aggregation of Biofuel-Producing Algae by the Bacterium Bacillus sp. Strain RP1137, Appl. Environ. Microbiol. 79 (2013) 6093-6101. doi:10.1128/AEM.01496-13.

[37] S.B. Ummalyma, E. Gnansounou, R.K. Sukumaran, R. Sindhu, A. Pandey, D. Sahoo, Bioflocculation: An alternative strategy for harvesting of microalgae - An overview, Bioresour. Technol. 242 (2017) 227-235. doi:10.1016/j.biortech.2017.02.097.

[38] H. Tang, M. Chen, K.Y. Simon Ng, S.O. Salley, Continuous microalgae cultivation in a photobioreactor, Biotechnol. Bioeng. 109 (2012) 2468-2474. doi:10.1002/bit.24516.

[39] R. Honda, Y. Teraoka, M. Noguchi, S. Yang, Optimization of Hydraulic Retention Time and Biomass Concentration in Microalgae Biomass Production from Treated Sewage with a Membrane Photobioreactor, J. Water Environ. Technol. 15 (2017) 1-11. doi:10.2965/jwet.15-085. 
[40] R. Honda, J. Boonnorat, C. Chiemchaisri, W. Chiemchaisri, K. Yamamoto, Carbon dioxide capture and nutrients removal utilizing treated sewage by concentrated microalgae cultivation in a membrane photobioreactor, Bioresour. Technol. 125 (2012) 59-64. doi:10.1016/j.biortech.2012.08.138.

[41] H. Wang, W. Zhang, L. Chen, J. Wang, T. Liu, The contamination and control of biological pollutants in mass cultivation of microalgae, Bioresour. Technol. 128 (2013) 745-750. doi:10.1016/j.biortech.2012.10.158.

[42] E. Kazamia, D.C. Aldridge, A.G. Smith, Synthetic ecology - A way forward for sustainable algal biofuel production?, J. Biotechnol. 162 (2012) 163-169. doi:10.1016/j.jbiotec.2012.03.022.

[43] G. Padmaperuma, R.V. Kapoore, D.J. Gilmour, S. Vaidyanathan, Microbial consortia: a critical look at microalgae co-cultures for enhanced biomanufacturing, Crit. Rev. Biotechnol. 38 (2018) 690-703. doi:10.1080/07388551.2017.1390728.

[44] A.P. Dean, D.C. Sigee, B. Estrada, J.K. Pittman, Using FTIR spectroscopy for rapid determination of lipid accumulation in response to nitrogen limitation in freshwater microalgae, Bioresour. Technol. 101 (2010) 4499-4507. doi:10.1016/j.biortech.2010.01.065.

[45] H. Wagner, Z. Liu, U. Langner, K. Stehfest, C. Wilhelm, The use of FTIR spectroscopy to assess quantitative changes in the biochemical composition of microalgae., J. Biophotonics. 3 (2010) $557-$ 66. doi:10.1002/jbio.201000019.

[46] J.J. Mayers, K.J. Flynn, R.J. Shields, Rapid determination of bulk microalgal biochemical composition by Fourier-Transform Infrared spectroscopy, Bioresour. Technol. 148 (2013) 215-220. doi:10.1016/j.biortech.2013.08.133.

[47] K.K. Sharma, H. Schuhmann, P.M. Schenk, High lipid induction in microalgae for biodiesel production, Energies. 5 (2012) 1532-1553. doi:10.3390/en5051532.

[48] L.E. de-Bashan, Y. Bashan, M. Moreno, V.K. Lebsky, J.J. Bustillos, Increased pigment and lipid content, lipid variety, and cell and population size of the microalgae Chlorella spp. when coimmobilized in alginate beads with the microalgae-growth-promoting bacterium Azospirillum brasilense , Can. J. Microbiol. 48 (2002) 514-521. doi:10.1139/w02-051. 
[49] H.U. Cho, Y.M. Kim, J.M. Park, Enhanced microalgal biomass and lipid production from a consortium of indigenous microalgae and bacteria present in municipal wastewater under gradually mixotrophic culture conditions, Bioresour. Technol. 228 (2017) 290-297. doi:10.1016/j.biortech.2016.12.094.

[50] F.J. Choix, L.E. De-Bashan, Y. Bashan, Enhanced accumulation of starch and total carbohydrates in alginate-immobilized Chlorella spp. induced by Azospirillum brasilense: II. Heterotrophic conditions, Enzyme Microb. Technol. 51 (2012) 300-309. doi:10.1016/j.enzmictec.2012.07.012.

[51] M. Do Nascimento, M. de los A. Dublan, J.C.F. Ortiz-Marquez, L. Curatti, High lipid productivity of an Ankistrodesmus-Rhizobium artificial consortium, Bioresour. Technol. 146 (2013) 400-407. doi:10.1016/j.biortech.2013.07.085.

[52] T. Jauffrais, H. Agogué, M.-P. Gemin, L. Beaugeard, V. Martin-Jézéquel, Effect of bacteria on growth and biochemical composition of two benthic diatoms Halamphora coffeaeformis and Entomoneis paludosa, J. Exp. Mar. Bio. Ecol. 495 (2017) 65-74. doi:10.1016/j.jembe.2017.06.004.

[53] S.-H. Lee, C.-Y. Ahn, B.-H. Jo, S.-A. Lee, J.-Y. Park, K.-G. An, H.-M. Oh, Increased microalgae growth and nutrient removal using balanced N:P ratio in wastewater., J. Microbiol. Biotechnol. 23 (2013) 92-8. http://www.ncbi.nlm.nih.gov/pubmed/23314374.

[54] K.H. Ryu, M.-G. Sung, B. Kim, S. Heo, Y.K. Chang, J.H. Lee, A mathematical model of intracellular behavior of microalgae for predicting growth and intracellular components syntheses under nutrientreplete and -deplete conditions, Biotechnol. Bioeng. 115 (2018) 2441-2455. doi:10.1002/bit.26744. 